\title{
Parents' Monitoring-Relevant Knowledge, Involvement with Deviant Peers and Substance Use: Time-Variant and Long-Term Associations among Adolescents Aged 12-17
}

\author{
Eva-Lotta Nilsson $^{1}$ \\ ${ }^{1}$ Malmö University, Malmö, Sweden \\ Correspondence: Eva-Lotta Nilsson, Malmö University, Faculty of health and society. 20506 Malmö, Sweden.
}

Received: August 19, 2016

doi:10.11114/ijsss.v4i10.1876
Accepted: September 6, 2016

Available online: September 13, 2016

URL: http://dx.doi.org/10.11114/ijsss.v4i10.1876

\begin{abstract}
With longitudinal data, drawn from the Malmö Individual and Neighbourhood Development Study (MINDS), time-variant and long-term associations between parents' monitoring-relevant knowledge, involvement with deviant peers and substance use are examined among a sample of 190 adolescents followed from 12 to 17 years of age. The main results show that parents knowing where their children are, what they are doing, and whom they are with, is beneficial in providing protection against involvement with deviant peers, which in turn appear to be important to the development of substance use. These results apply to both time-variant and long-term associations.
\end{abstract}

Keywords: deviant peers, longitudinal study, parents' monitoring-relevant knowledge, substance use

\section{Introduction}

Relationships with parents and peers have long been recognized as central elements of the adolescent experience and in the field of criminological research, parents and peers are well known to be two of the most important social influences when it comes to explaining deviant behavior during adolescence (e.g. Smetana, Champione-Barr, \& Metzger, 2006; Thornberry \& Krohn, 2005; Van Ryzin, Fosco, \& Dishion, 2012). Adolescence, however, is a period that involves numerous changes at both the individual and social levels (Steinberg \& Silk, 2002; Smetana et al., 2006; Mulvey, 2014), and the locus of interaction and social influence generally shifts from the family to peer networks during this period of life (e.g. Henry, Tolan, \& Gorman-Smith, 2001). In the area of criminological theory, most theorists are not explicit about whether the effects of their key variables vary over the course of adolescence, and most studies employ cross-sectional designs. However, there has been an increase in the number of criminological studies based on a developmental perspective and this (multidisciplinary) perspective is becoming more influential (Morizot \& Kazemian, 2015). The importance of the developmental perspective in criminology is linked to the idea that the etiological factors that affect delinquency and other deviant behaviors may vary across different developmental periods in the life course (Le Blanc \& Loeber, 1998; Piquero, Farrington, \& Blumstein, 2003).

One important change that occurs during the period of adolescence is that individuals' activities, interests, and peer groups usually change and expand, and more time is generally spent away from direct adult supervision (e.g. Laird et al., 1998; Sullivan, 2013). As a consequence, parents shift from direct supervision to more distal forms of monitoring in order to obtain information. One central construct that captures how well parents are able to keep track of what their children are up to is parental knowledge. In the literature, a strong and consistent link has been established between parents' monitoring-relevant knowledge and risky behaviors among youth (for a review see Crouter \& Head, 2002). A lack of knowledge is associated with both a higher level of substance use and a greater risk of being involved with, and influenced by, deviant peers (Barnes et al., 2006; Laird et al., 2008; Veronneau \& Dishion, 2010). Several studies provide evidence that the association between adolescent and peer deviant behavior (e.g. substance use) is stronger when parents are less aware of their adolescents' activities (Dishion et al., 1995; Rai et al., 2003; Wood et al., 2004). Even when controlling for a broad array of possible confounding variables, parents' monitoring-relevant knowledge remains an important protective factor in relation to youth development (Lippold, Greenberg, \& Collins, 2014).

Over the past decade, scholars have explored a variety of possible links between parent and peer influences and their associations with adolescent behavior as these relationships develop over the course of adolescence. In research 
studying time-varying effects of parents and peers, the results are mixed (see Jang, 1999). On one hand, it has been suggested that the significance of parent and peer influences in the explanation of different forms of deviant behavior varies across different stages of adolescence (e.g. Van Ryzin et al., 2012; Worthen, 2012). There are studies indicating that while parents are most influential during early adolescence, the influence of friends becomes much greater during middle and late adolescence (Ingram et al., 2007; Warr, 2005; Worthen, 2012). On the other hand, there is research suggesting that even though peers become more important as young people reach adolescence, they do not displace parents as sources of influence on teenage behavior (Brown \& Bakken, 2011). In research integrating parenting and peer influences into a broader framework to explain adolescent behavior, peer factors are often modeled as mediators between family factors and the outcome of interest. In most cases, the mediating variable is the degree of association with deviant peers (Brown $\&$ Bakken, 2011). Also, results on how these variables are related to, and the ways in which they affect, substance use are mixed. For example, some studies support the notion that parenting affects adolescent substance use both directly and through the way it may promote the influence of deviant peers (Dishion et al., 1995). Further, while some researchers have found that the family environment and parenting exert an indirect effect on substance use, which works via association with deviant peers (Nash, McQueen, \& Bray, 2005; Oxford et al., 2001), others have failed to find such mediating effects (Buehler, 2006).

Longitudinal work studying family and peer influences on deviant behavior indicates that effective monitoring-relevant strategies by parents early in a child's life are related to the development of fewer behavioral problems in adolescence (Gardner, Sonuga-Barke, \& Sayal, 1999; Van Ryzin et al., 2012). For example, poor monitoring and family attachment during preadolescence have been found to have an enduring effect on drug use during adolescence (Brook \& Cohen, 1992; Chilchoat \& Anthony, 1996).

Against this background, longitudinal data relating to adolescents from 12 to17 years of age will here be examined in order to address the issue of potential time-variant and long-term associations between parents' monitoring-relevant knowledge, involvement with deviant peers and substance use. The aim of the present study is to examine: 1) whether there are time-variant associations between parents' monitoring-relevant knowledge, involvement with deviant peers and substance use, 2) whether the association between monitoring-relevant knowledge and substance use involves an indirect effect that works via deviant peer affiliations and whether the strength of this mediation effect varies at different time-points, and 3) whether there are long-term associations between monitoring-relevant knowledge and later involvement with deviant peers and adolescent substance use.

\section{Methods}

\subsection{Sample}

The data employed in the study are drawn from the Malmö Individual and Neighbourhood Development study (MINDS), which was initiated in 2007. MINDS is a longitudinal research project with the goal of following a sample of adolescents born in 1995 (approximately 20 percent of the cohort) and living in Malmö in 2007, between the ages of 12 and 20. The total sample consists of 525 adolescents. The overall aim of the MINDS project is to contribute to a better understanding of the causes and prevention of young people's offending, but also to study how exposure to social settings affects other aspects of adolescent development and health. MINDS is modelled on the Peterborough Adolescent and Young Adult Development study (PADS+) conducted at Cambridge University's Institute of Criminology (Wikström et al., 2012), but some adjustments have been made to adapt the study to the specific aims of the MINDS project.

For the purposes of this study, multiple waves of data are required. The subsample employed in the current study is drawn from a data set focused on the parents who were interviewed in the initial phase of the study and whose children then participated in the following three waves of data collection. This final subsample, with data from both the parent and child surveys, consists of 190 parents and their children. Of this sample 52 percent are boys and 48 percent girls. Approximately 73 percent of the respondents had a completely native background (both parents from Sweden). 64 percent of the respondents lived with both of their parents and 35 percent lived in a single parent family. According to the parents' own reports, about 82 percent of the interviewed parents had a job, and of these, 74 percent were in full-time employment. 48 percent of the interviewed parents have university education (Note 1 ).

\subsection{Procedure}

The parent interviews comprised the first wave of data collection and were administered in the form of one-to-one interviews with a guardian of the child (154 mothers, and 36 fathers) conducted using an interviewer-led questionnaire. The parent interviews were conducted in 2007-2008 (when the children were 12-13 years old).

The adolescents' questionnaires were for the most part completed during regular school hours at sessions administered by trained research assistants. The respondents were informed that participation was voluntary, and they were assured 
that their answers would not be revealed to their parents, teachers, or anyone else. Teachers were not present. The first wave of data collection with the adolescents was carried out in 2009-2010, at age 14-15 (hereafter referred to as T1), the second wave was carried out in 2010-2011, at age 15-16 (hereafter referred to as T2), and the third wave was conducted in 2011-2012, at age 16-17 (hereafter referred to as T3).

\subsection{Measures}

Adolescent substance use is measured using five items. The adolescents answered questions about whether they, over the course of the past year; had drunk alcohol until they became drunk / smoked cigarettes / tried snuff / tried sniffing (for example gas or glue) / tried drugs. The response alternatives for these items were: No / yes, once or twice / yes, a times / yes many times / yes, very many times. The resulting scale has an Alpha value of .64 at T1, .66 at T2, and .61 at T3. In the current sample, 41.6 percent of the adolescents had tried/used at least one of the substances listed above during the past year at T1, 61.6 percent at T2, and 68.9 percent at T3 (Note 2).

Parents' monitoring-relevant knowledge is an additive scale based on three items describing the parents', or the adolescents', perceptions of their parents' knowledge of the youth's whereabouts, activities, and peers (Note 3). The parents were asked if they knew; where their child hangs out in their free time (i.e. at a friend's house, in a park) / what their child does, alone or with friends, in his/her free time / which friends their child hangs out with in his/her free time. The adolescents where asked the same questions, but they were asked about whether their parents knew about their whereabouts, activities, and peers. The response alternatives for these items were: Yes, always / yes, most of the time / yes, sometimes / no, never. A high score on the measure implies a high level of parental knowledge. The alpha reliabilities for this three-item scale were .73 at the parent interviews, .76 at T1, .81 at T2, and .78 at T3. The adolescents in the sample reported that their parents generally knew a lot about their whereabouts, activities and peers. In the literature, there are a number of measurement issues which have clouded the distinction between parental knowledge of youth activities and parental attempts to monitor youth. The type of measure used in this study has often been labeled and interpreted as reflecting monitoring or supervision, indicating an active monitoring of children's activities on the part of parents (see Kerr and Stattin, 2000; Stattin and Kerr, 2000). The literature has also discussed how parents obtain this kind of information, i.e. whether it is freely disclosed to them by their children, or whether it is solicited ty the parents themselves (see Kerr \& Stattin, 2000). No information about how the parents obtained this information is available in the current study. Some studies have indicated that child disclosure constitutes the main source of parental knowledge (Stattin \& Kerr, 2000). This makes it pertinent to ask what it is that leads children to voluntarily disclose information to their parents. The research contains studies which strongly indicate that child disclosure is based and dependent on the quality of the parent-child relationship (Crouter \& Head, 2002; Fletcher, Steinberg, \& Williams-Wheeler, 2004; Kerr \& Stattin, 2000; Kerr, Stattin \& Trost, 1999; Stattin \& Kerr, 2000). Thus the monitoring-relevant knowledge of parents may be viewed as primarily constituting a measure of the nature of the parent-child relationship rather than as a measure of active monitoring or other behaviors on the part of parents.

Involvement with deviant peers: The adolescent respondents answered a series of items focused on patterns of substance use and antisocial behaviors among their friends (reflecting a general deviant peer process construct). The involvement with deviant peers variable is an additive scale based on six items. The respondents were asked whether some of their closest friends sometimes: skipped school / got drunk / used drugs (e.g. cannabis) and/or sniffed glue / shoplifted or stole from other people / vandalized things / got into fistfights (where someone got hurt). The response alternatives for these items were: no, never / yes, sometimes / yes, quite often / yes, very often. This scale has an Alpha level of .76 at $\mathrm{T} 1, .79$ at T2 and T3. A high score on the measure implies a high level of deviant peer affiliations.

There are no signs of multicollinearity between the study variables, since the highest variance inflation factor score was 2.43, which is below the acceptable threshold. The level of missing data is low, with at most eight missing cases (4.8\%) on one of the study variables (Involvement with deviant peers at T2).

\subsection{Statistical Analyses}

Initially, paired-samples T-tests were conducted in order to examine changes in mean levels of the variables between time-points. Zero-order correlations between all the study variables were obtained in order to examine bivariate relationships. To analyze the first research question, that of whether there are time-variant associations among the variables, a number of Ordinary Least Square (OLS) regression analyses were conducted separately for the three waves of data, focusing on both substance use and involvement with deviant peers as the outcome variables. In order to examine the second research question, that of the significance of possible indirect effects in these analyses, the study employed the Sobel method (Sobel, 1982). For the purpose of the third research question, a path analysis was specified and estimated in order to examine both the direct effects of parents' monitoring-relevant knowledge at T1 on substance use at T2 and T3, and the indirect effects of parents' monitoring-relevant knowledge at T1 on substance use at T2 and T3 via involvement with deviant peers at T2 and T3 and on substance use at T3 via prior substance use at T2. Model fit 
was assessed by means of the chi-square $\left(x^{2}\right)$, Comparative Fit Index (CFI) and Root Mean Square Error of Approximation (RMSEA) measures (Note 4).

\section{Results}

\subsection{Descriptive}

All study variables showed significant changes in mean levels over time (see Table 1). The level of parents' monitoring-relevant knowledge decreased significantly from age 12 to 16. From age 16-17, the adolescents reported a small but significant increase in the level of parents' monitoring-relevant knowledge. The adolescents also reported significant increases in levels of both involvement with deviant peers and substance use from T1 to T3.

Table 1. Descriptive Statistics and T-Tests of Study Variables

\begin{tabular}{|c|c|c|c|c|c|c|c|}
\hline & \multicolumn{3}{|c|}{ Parents (age 12-13) } & \multicolumn{4}{|c|}{ Time 1 (age 14-15) } \\
\hline Variable & Range & Mean & SD & Range & Mean & SD & $t(\mathrm{DF})$ \\
\hline Parental knowledge & $2-9$ & 7.49 & 1.45 & $0-9$ & 6.07 & 1.98 & $9.15 * * *(187)$ \\
\hline Deviant peers & & & & $0-15$ & 2.61 & 2.68 & \\
\hline \multirow{3}{*}{ Substance use } & & & & $0-11$ & 1.43 & 2.31 & \\
\hline & \multicolumn{3}{|c|}{ Time 2 (age $15-16$ ) } & \multicolumn{4}{|c|}{ Time 3 (age 16-17) } \\
\hline & Range & Mean & $\mathrm{SD} \quad t(\mathrm{DF})$ & Range & Mean & SD & $t(\mathrm{DF})$ \\
\hline Parental knowledge & $1-9$ & 5.70 & $1.96 \quad 3.48 * * *(181)$ & $0-9$ & 6.19 & 1.86 & $-3.67 * * *(181)$ \\
\hline Deviant peers & $0-16$ & 3.20 & $2.66-3.22 * *(178)$ & $0-17$ & 3.79 & 3.19 & $-2.90 * *(181)$ \\
\hline Substance use & $0-14$ & 2.77 & $3.21-9.13 * * *(189)$ & $0-14$ & 3.30 & 3.60 & $-3.37 * * *(181)$ \\
\hline
\end{tabular}

Description: High score on scales indicate high level of parental knowledge, high level of involvement with deviant peers, and high level of substance use. $t$-tests: T1 refers to changes in mean levels from parental interviews to T1. T2 refers to changes from $\mathrm{T} 1$, and $\mathrm{T} 3$ refers to changes from $\mathrm{T} 2 .{ }^{*} \mathrm{p}<.05, * * \mathrm{p}<.01, * * * \mathrm{p}<.001$.

\subsection{Bivariate Correlations}

The bivariate correlations presented in Table 2 show that parents' reports of monitoring-relevant knowledge at age 12-13 were negatively and significantly correlated with both involvement with deviant peers and substance use at all other measurement points. Parental reports of their monitoring-relevant knowledge were positively and significantly correlated with monitoring-relevant knowledge at T1 and T2, but were uncorrelated with parents' monitoring-relevant knowledge at T3. Parents' monitoring-relevant knowledge at $\mathrm{T} 1, \mathrm{~T} 2$ and $\mathrm{T} 3$ were negatively and significantly correlated with the adolescents' involvement with deviant peers and substance use at all measurement points, with the exception of parents' monitoring-relevant knowledge at T3, which was uncorrelated with either involvement with deviant peers or substance use at $\mathrm{T} 1$.

Involvement with deviant peers and substance use were positively and significantly correlated at all measure point, both within and between time-points. The strongest correlations, however, were between the same variables measured at different points, for example between substance use at $\mathrm{T} 1$ and $\mathrm{T} 2(\mathrm{r}=.78)$, between substance use at $\mathrm{T} 2$ and $\mathrm{T} 3(\mathrm{r}=.81)$, and between involvement with deviant peers at $\mathrm{T} 2$ and $\mathrm{T} 3(\mathrm{r}=.67)$.

Table 2. Bivariate Correlations of Study Variables

\begin{tabular}{|c|c|c|c|c|c|c|c|c|c|}
\hline Variable & 1. & 2. & 3. & 4. & 5. & 6. & 7. & 8. & 9. \\
\hline \multicolumn{10}{|l|}{ 1.Parental knowledge(P) } \\
\hline 2.Parental knowledge(T1) & $.26^{* * *}$ & & & & & & & & \\
\hline 3.Deviant peers(T1) & $-.25 * * *$ & $-.37 * * *$ & & & & & & & \\
\hline 4.Substance use(T1) & $-.25 * * *$ & $-.29 * * *$ & $.64 * * *$ & & & & & & \\
\hline 5.Parental knowledge(T2) & $.25 * * *$ & $.65^{* * *}$ & $-.25 * * *$ & $-.19 * *$ & & & & & \\
\hline 6.Deviant peers(T2) & $-.23 * *$ & $-.40 * * *$ & $.64 * * *$ & $.59 * * *$ & $-.42 * * *$ & & & & \\
\hline 7.Substance use(T2) & $-.30 * * *$ & $-.36 * * *$ & $.53^{* * *}$ & $.78 * * *$ & $-.36^{* * * *}$ & $.68 * * *$ & & & \\
\hline 8.Parental knowledge(T3) & .13 & $.48^{* * *}$ & -.10 & -.00 & $.52 * * *$ & $-.27 * * *$ & $-.16^{*}$ & & \\
\hline 9.Deviant peers(T3) & $-.23 * * *$ & $-.30 * * *$ & $.53 * * *$ & $.38 * * *$ & $-.36^{* * *}$ & $.67 * * *$ & $.45^{* * *}$ & $-.36 * * *$ & \\
\hline 10.Substance use(T3) & $-.24 * * *$ & $-.40 * * *$ & $.50 * * *$ & $.66 * * *$ & $-.39 * *$ & $.60 * * *$ & $.81 * * *$ & $-.24 * * *$ & $.51 * * *$ \\
\hline
\end{tabular}


Overall, the results presented in Table 2 suggest that when parents are aware of where their children are, what they are doing, and with whom, adolescents are less likely to be involved with deviant peers or in substance use, while the higher level of adolescent involvement with deviant peers, the more likely these adolescents are to engage in substance use. These correlations between the study variables are significant both when measured at the same time point and when measured at different times.

\subsection{Associations Between Study Variables by Time-Point}

A number of OLS regression were conducted in order to analyze the relationship between parents' monitoring-relevant knowledge, involvement with deviant peers and substance use separately at T1, T2, and T3. In all waves of the data, parents' monitoring-relevant knowledge has a negative effect on substance use (T1: $\beta=-.29 * * *$; T2: $\beta=-.36 * * *$; T3: $\beta=$ $-.24 * * *)$. This indicates that the less parents know about where their children are, what they are doing and with whom, the more likely their children are to be using substances. However, when involvement with deviant peers is included in the models, the effect of parents' monitoring-relevant knowledge becomes weaker in all waves of the data. In each wave, parents' monitoring-relevant knowledge has a stronger effect on affiliations with deviant peers than on substance use. The highest proportion of the variance in substance use explained by a low level of parents' monitoring-relevant knowledge and involvement with deviant peers is found at $\mathrm{T} 2(47.9 \%)$, while the lowest proportion of explained variance is found at T3 $(26.7 \%)$.

In the mediation models, see Figure 1, the results are similar across all waves of the study. The direct effect of parents' monitoring-relevant knowledge on substance use is very small and non-significant in all waves. The association between parents' monitoring-relevant knowledge and involvement with deviant peers is stronger than between monitoring-relevant knowledge and substance use; however, across all waves of the study, the strongest correlation noted is that between involvement with deviant peers and substance use. The analyses show that 75.8 percent of the effect of monitoring-relevant knowledge on substance use was mediated through involvement with deviant peers at T1, 69.8 percent at T2, and 70.3 percent at T3. Sobel tests were conducted to test the significance of these indirect effects, with these showing that the mediation effects were significant at all times $\left(\mathrm{T} 1 ; \mathrm{z}=-3.79 * * *, \mathrm{~T} 2 ; \mathrm{z}=-4.83^{* * *}, \mathrm{~T} 3 ; \mathrm{z}=-3.10^{* * *}\right)$.

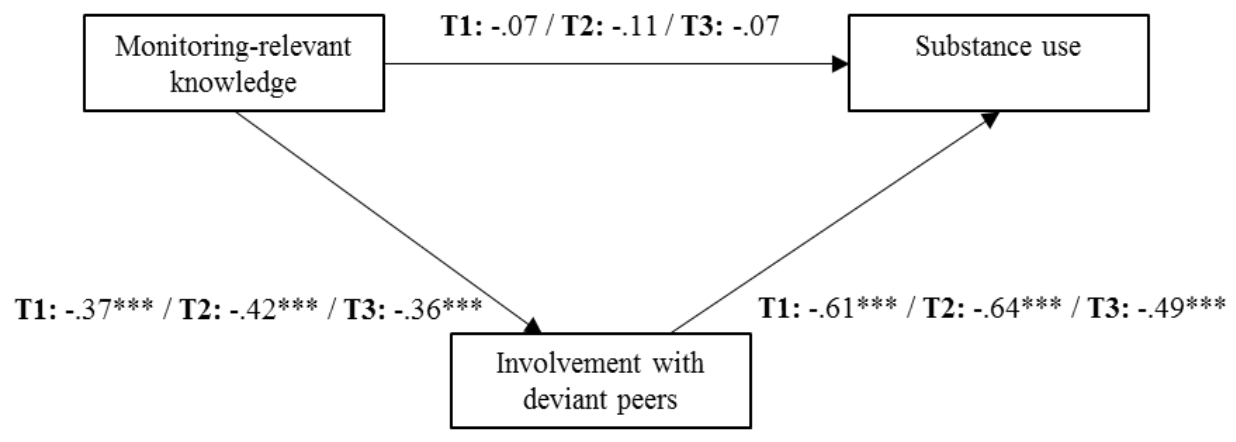

Figure 1. Associations between Study Variables by Time-Point.

Description: Standardized coefficients from OLS regression analysis testing associations between parents' monitoring-relevant knowledge, involvement with deviant peers and substance use separately for T1, T2 and T3. *p<.05, $* * \mathrm{p}<.01, * * * \mathrm{p}<.001$.

\subsection{Longitudinal Model of the study Variables}

A path analysis was conducted to examine a longitudinal model of the study variables. As can be seen in Figure 2, high level of parents' monitoring-relevant knowledge at T1 were associated with a lower likelihood of involvement with deviant peers at $\mathrm{T} 2$, and also with lower levels of substance use at T3 (although this effect was only marginally significant). There were no significant direct pathways from parents' monitoring-relevant knowledge (T1) to substance use at T2 or involvement with deviant peers at T3. Predictions from T2 and T3 indicated continuity of substance use over time, as well as continuity of involvement with deviant peers over time (Note 5).

The analysis also shows that parents' monitoring-relevant knowledge was indirectly associated with substance use at T2 via involvement with deviant peers at $\mathrm{T} 2$. There was also a significant indirect path between parents' monitoring-relevant knowledge and substance use at $\mathrm{T} 3$ via involvement with deviant peers at $\mathrm{T} 2$ and $\mathrm{T} 3$.

These findings indicate that parents' monitoring-relevant knowledge is related to substance use in later adolescence. However, and perhaps more importantly, parents' monitoring-relevant knowledge seems to be an essential part of preventing children from associating with deviant peers, which seems to be instrumental in the development and 
maintenance of substance use.

Time 3, age 16-17

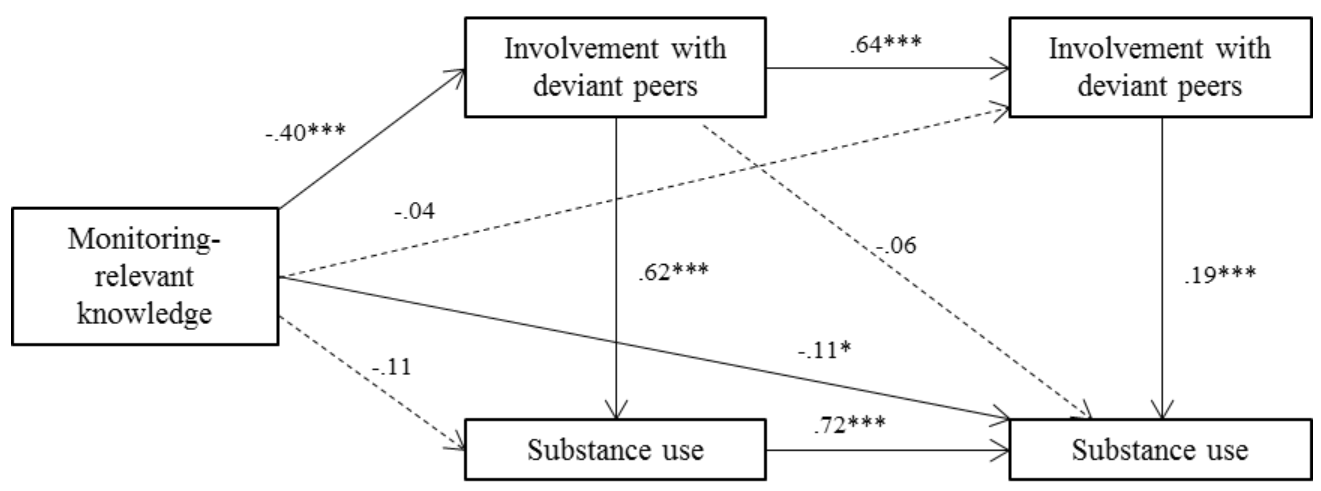

Figure 2. Longitudinal Model of the Study Variables.

Description: Standardized path coefficients testing associations between parents' monitoring-relevant knowledge at T1, involvement with deviant peers and substance use at T2 and T3. Model fit $x(2)=.037, \mathrm{p}=.85 ; \mathrm{CFI}=$

1.00; RMSEA $=.00 . * \mathrm{p}<.05, * * \mathrm{p}<.01, * * * \mathrm{p}<.001$.

\section{Discussion}

The main results from this study shed light on the benefits produced by parents' knowing where their adolescents are, what they are doing, and whom they are with. This knowledge appears to be beneficial in providing protection against the emergence of risky influences, such as involvement with deviant peers, which in turn appear to be important to the development of substance use. These results apply to both time-variant and long-term associations.

While some of the results reported by the present study were to be expected, others are more of a surprise. The bivariate tests conducted by the study validate the nature of some of the expected associations among the study variables namely that youths whose parents have high levels of knowledge about their activities are less likely to be involved with deviant peers and to engage in substance use. Involvement with deviant peers increases the risk for substance use. The finding of significant changes in the mean levels of the study variables with increasing age was also expected. However, even though we would expect to find a decrease in the level of parental knowledge over time (e.g. Janssen, Dekovic, \& Brunisma, 2014; Wikström et al., 2012), there has been some discussion about what such changes during adolescence in the patterns of parents' monitoring-relevant knowledge might mean. While some have argued that lower levels of monitoring-relevant knowledge might be an indication of parents granting their children more freedom and permitting greater autonomy (Steinberg \& Silk, 2002), others have problematized this decrease in knowledge by noting that knowledge is actually increasingly important during this period, because adolescents spend more time away from home, and obtaining knowledge might be the most important way for parents to keep track of what their children are doing (Smetana et al., 2006).

When it comes to the time-varying effects, it was somewhat surprising that the influences of parents' monitoring-relevant knowledge and of involvement with deviant peers did not vary more over time, since previous studies have found that parents are usually more influential in the earlier stages of adolescence and that the influences of friends grow stronger from early to late adolescence (e.g. Warr, 1993; Worthen, 2012). In this study, the patterns found in relation to the influence of parents' monitoring-relevant knowledge and of involvement with deviant peers were similar in all three waves of the study, that is, the association between parents' monitoring-relevant knowledge and substance use was mediated via involvement with deviant peers. With the exception of this failure to find more variation in the nature of the associations between different social influences over time, there are a number of reasons why these results are not surprising per se. For example, during adolescence, peer factors typically dominate the predictive relationship when they are included in models alongside other predictors (Brook \& Cohen, 1992; Steinberg, Fletcher, \& Darling, 1994). In addition, since most adolescent substance use takes place within a peer social environment, peer influence is believed to have a proximal effect on substance use (Fletcher, Darling, \& Steinberg, 1995). At the same time, the results of this study do show that the associations are time-variant to some degree, since the strongest effects were measured for all of the associations at $\mathrm{T} 2$, which indicates that adolescents are more susceptible to social 
influences at age 15-16.

Further, the longitudinal path analysis indicates that parents' monitoring-relevant knowledge in early adolescence appears to shape the landscape for involvement with deviant peers and substance use in later adolescence. Parents' monitoring-relevant knowledge in earlier adolescence was found to be associated with substance use later on in adolescence in different ways, but mainly indirectly via involvement with deviant peers. Essentially, these results indicate that developing good parenting practices/relations at an early age, e.g. in the form of knowledge of one's children's whereabouts, activities, and peers, can protect youths from risky influences, most notably involvement with deviant peers.

A number of limitations associated with the current study should be noted. Although the sample is based on the reports of both parents and adolescents, the parent interviews were only conducted at one time, and it has therefore not been possible to analyze changes over time in parental reports nor in the correlations between child and parent reports. Further, the data in this study primarily rely on adolescent perceptions of their parents' monitoring-relevant knowledge and the deviant behavior of their peers. When it comes to adolescent perceptions of their peers, one important limitation that has been noted is that adolescent reports may overestimate the similarity between their own behavior and that of their peers (Aseltine, 1995; Urberg, Cheng, \& Shyu, 1991). Further, no measures were included of how much time the adolescents spend with deviant friends or of whether the adolescents were in fact engaging in substance use in the company of their identified friends. Data of this kind on risk settings would add valuable information to the analysis. In addition, the study focused on a relatively short period of time, which may have implications for the results when viewed in relation to a developmental perspective. The focus on an age range that is for the most part restricted to middle adolescence may have led to an underestimation of the level of variability in parent and peer influences.

Despite these limitations, the present study also has a number of strengths and it contributes to the literature in several ways. For instance, the present study has a longitudinal design, and the study sample has been restricted to those individuals who have participated in every wave of the data collection process. Further, a developmental model is important when it comes to informing prevention and treatment programs, since the results from studies with a developmental focus may contribute important information regarding when to use prevention measures, whom interventions should be directed at, and which factors should be emphasized. Improved knowledge of the impact of various risk and protective factors at different stages of adolescence may therefore provide useful guidance for intervention efforts.

Overall, it appears that parents' monitoring-relevant knowledge can reduce the chances of negative relationships developing among youth; however, friends constitute strong models of deviant behavior. The findings indicate that family factors continue to be important predictors in the explanation of substance use during adolescence, even in the presence of peer factors. Therefore, although peer influences might be important targets for adolescent interventions, the risks produced by deviant peer-group affiliations might also be addressed by means of interventions with families.

\section{References}

Aseltine, R. H. (1995). A Reconsideration of Parental and Peer Influences on Adolescent Deviance. Journal of Health and Social Behavior, 36, 103-121.

Barnes, G., Hoffman, J., Welte, W., Farrell, M., \& Dintcheff, B. (2006). Effects of parental monitoring and peer deviance on substance use and delinquency. Journal of Marriage and Family, 68, 1084-1104. http://dx.doi.org/10.1111/j.1741-3737.2006.00315.x

Brook, J. S., \& Cohen, P. (1992). A Developmental Perspective on Drug Use and Delinquency. In: Facts, Frameworks, and Forecasts. Advances in Criminological Theory. Ed: McCord, J. Transaction Publishers: New Brunswick, 3, 231-251.

Brown, B. B., \& Bakken, J. P. (2011). Parenting and Peer Relationships: Reinvigorating Research on Family-Peer Linkages in Adolescence. Journal of Research on Adolescence, 21, 153-165. http://dx.doi.org/10.1111/j.1532-7795.2010.00720.x

Buehler, C. (2006). Parents and Peers in Relation to Early Adolescent Problem Behavior. Journal of Marriage and Family, 68, 109-124. http://dx.doi.org/10.1111/j.17413737.2006.00237.x

Chilcoat, H. D., \& Anthony, J. C. (1996). Impact of Parent Monitoring on Initiation of Drug Use Through Late Childhood. Journal of the American Academy of Child \& Adolescent Psychiatry, 35, 91-100. http://dx.doi.org/10.1097/00004583-199601000-00017

Crouter, A., \& Head, M. (2002). Parental knowledge and knowledge of children. In M. Bornstein (Ed.), Handbook of parenting, 3, 461-483. Mahwah, New Jersey: Lawrence Erlbaum. 
Dishion, T. J., Capaldi, D., Spracklen, K. M., \& Li, F. (1995). Peer ecology of male adolescent drug use. Development and Psychopathology, 7, 803-824. http://dx.doi.org/10.1017/S0954579400006854

Fletcher, A. C., Darling, N., \& Steinberg, L. (1995). Parental Monitoring and Peer Influences on Adolescent Substance Use. In: Coercion and Punishment in Long Term Perspectives. Ed: McCord, J. Cambridge University Press. New York.

Fletcher, A., Steinberg, L., \& Williams-Wheeler, M. (2004). Parental Influences on Adolescent Problem Behavior: Revisiting Stattin and Kerr. Child Development, 75, 781-796. http://dx.doi.org/10.1111/j.1467-8624.2004.00706.x

Gardner, F. E. M., Sonuga-Barke, E. J., \& Sayal, K. (1999). Parents anticipating misbehavior: An observational study of strategies parents use to prevent conflict with behaviour problem children. Journal of Child Psychology and Psychiatry, 40, 1185-1196.

Henry, D. B., Tolan, P. H., \& Gorman-Smith, D. (2001). Longitudinal Family and Peer Group Effects on Violence and Nonviolent Delinquency. Journal of Clinical Child Psychology, 30, 172-186. http://dx.doi.org/10.1207/S15374424JCCP3002_5

Ingram, J. R., Patchin, J. W., Huebner, B. M., McCluskey, J. D., \& Bynum, T. S. (2007). Parents, Friends, and Serious Delinquency. An Examination of Direct and Indirect Effects Among At-Risk Early Adolescents. Criminal Justice Review, 32, 380-400. http://dx.doi.org/10.1177/0734016807311436

Jang, S. J. (1999). Age Varying Effects of Family, School and Peers on Delinquency: Multilevel Modeling Test of Interactional Theory. Criminology, 37, 643-686. http://dx.doi.org/10.1111/j.1745-9125.1999.tb00499.x

Janssen, H. J., Dekovic, M., \& Brunisma, G. J. N. (2014). Parenting and time adolescents spend in criminogenic settings: a between- and within-person analysis. British Journal of Criminology, 54, 551-567. http://dx.doi.org/10.1093/bjc/azu032

Keijsers, L., Branje, S. J., Vandervalk, I. E., \& Meeus, W. (2010). Reciprocal effects between parental solicitation, parental control, adolescent disclosure and adolescent delinquency. Journal of Research on Adolescence, 20, 88-113. http://dx.doi.org/10.1111/j.1532-7795.2009.00631.x

Kerr, M., \& Stattin, H. (2000). What parents know, how they know it, and several forms of adolescent adjustment: Further support for the reinterpretation of monitoring. Developmental Psychology, 36, 366-380. http://dx.doi.org/10.1037/0012-1649.36.3.366

Kerr, M., Stattin, H., \& Trost, K., (1999). To know you is to trust you: parents' trust is rooted in child disclosure of information. Journal of Adolescence, 22, 737-752. http://dx.doi.org/10.1006/jado.1999.0266

Kline, R. B. (2005). Principles and Practice of Structural Equation Modeling ( $2^{\text {nd }}$ Edition ed.). New York: The Guilford Press.

Laird, R. D. Criss, M. M., Pettit G. S., Dodge, K. A., \& Bates J. E. (2008). Parents' monitoring knowledge attenuates the link between antisocial friends and adolescent delinquent behavior. Journal of Abnormal Child Psychology, 36, 299-310. http://dx.doi.org/10.1007/s10802-007-9178-4

Laird, R. D., Criss, M. M., Pettit, G. S., Dogde, K. A., \& Bates, J. E. (2003). Parents' monitoring-relevant knowledge and adolescents' delinquent behavior: Evidence of correlated developmental changes and reciprocal influences. Journal of Abnormal Psychology, 36, 299-310. http://dx.doi.org/10.1111/1467-8624.00566

Laird, R. D., Pettit, G. S., Dodge, K. A., \& Bates, J. E. (1998). The social ecology of school age child care. Journal of Applied Developmental Psychology, 19, 341-360. http://dx.doi.org/10.1016/S0193-3973(99)80044-6

Le Blanc, M., \& Loeber, R. (1998). Developmental criminology updated. In M. Tonry (Ed.), Crime and justice (Vol. 23, pp. 115-198). Chicago: University of Chicago Press.

Lippold, M. A., Greenberg, M. T, \& Collins, L. M. (2014). Youth Substance Use and Changes in Parental Knowledge-Related Behaviors During Middle School: A Person-Oriented Approach. Journal of Youth and Adolescence, 43, 729-744. http://dx.doi.org/10.1007/s10964-013-0010-x

Morizot, J., \& Kazeiman, L. (2015) Introduction: Understanding Criminal and Antisocial Behavior Within a Developmental and Multidisciplinary Perspective. In J. Morizot \& L. Kazeiman (Eds.). The Development of Criminal and Antisocial Behavior. Theory, Research and Practical Applications (pp.1-16). London: Springer.

Mulvey, E. P. (2014). Using Developmental Science to Reorient Our Thinking About Criminal Offending in Adolescence. Journal of Research in Crime and Delinquency, 1-13. http://dx.doi.org/10.1177/0022427814522249

Nash, S. G., McQueen, A., \& Bray, J. H. (2005). Pathways to adolescent alcohol use: Family environment, peer 
influence, and parental expectations. Journal of Adolescent Health, 37, 19-28. http://dx.doi.org/10.1016/j.jadohealth.2004.06.004

Oxford, M. L., Harachi, T. W., Catalano, R. F., \& Abbott, R. D. (2001). Preadolescent predictors of substance initiation: A test of both the direct and mediated effect of family social control factors on deviant peer associations and substance initiation. American Journal of Drug and Alcohol Abuse, 27, 599-616. http://dx.doi.org/10.1081/ADA-100107658

Piquero, A. R., Farrington, D. P., \& Blumstein, A. (2003). The criminal career paradigm. Crime and Justice: A Review of Research, 30, 359-506.

Rai, A. A., Stanton, B., Wu, Y., Li, X., Galbraith, J., \& Cottrell, L., et al. (2003). Relative influences of perceived parental monitoring and perceived peer involvement on adolescent risk behaviors: An analysis of six cross-sectional data sets. Journal of Adolescent Health, 33, 108-118. http://dx.doi.org/10.1016/S1054-139X(03)00179-4

Smetana, J. G., Champione-Barr, N., \& Metzger, A. (2006). Adolescent Development in Interpersonal and Societal Contexts. Annual Review of Psychology, 57, 255-84. http://dx.doi.org/10.1146/annurev-psych.57.102904.190124

Sobel, M. E. (1982). Asymptotic confidence intervals for indirect effects in structural equation models. Sociological Methodology, 13, 290-312.

Stattin, H., \& Kerr, M. (2000). Parental Monitoring: A Reinterpretation. Child Development, 71, 1072-1085. http://dx.doi.org/10.1111/1467-8624.00210

Steinberg, L., \& Silk, J. S. (2002). Parenting Adolescents. In M. H. Bornstein (ed.) Handbook of Parenting: Children and Parenting, Vol. 1, 103-33. Mahwah, NJ: Lawrence Erlbaum Associates, Inc.

Steinberg, L., Fletcher, A. \& Darling, N. (1994). Parental Monitoring and Peer Influences on Adolescent Substance Use. Pediatrics, 93, 1060-1064.

Sullivan, C. J. (2013). Individual, social, and neighborhood influences on the launch of adolescent antisocial behavior. Youth Violence and Juvenile Justice, 12, 103-120. http://dx.doi.org/10.1177/1541204013483779

Thornberry, T. P., \& Krohn, M. D. (2005). Applying interactional theory to the explanation of continuity and change in antisocial behavior. In D. P. Farrington (Ed.), Integrated developmental and life-course theories of offending (pp. 183-209). New Brunswick, NJ: Transaction.

Urberg, K. A., Cheng, C. H., \& Shyu, S. J. (1991). Grade changes in peer influence on adolescent cigarette smoking: A comparison of two measures. Addictive Behaviors, 16, 21-28. http://dx.doi.org/10.1016/0306-4603(91)90036-H

Van Ryzin, M. J., Fosco, G. M., \& Dishion, T. J. (2012). Family and peer predictors of substance use from early adolescence to early adulthood: An 11-year prospective analysis. Addictive Behaviors, 37, 1314-1324. http://dx.doi.org/10.1016/j.addbeh.2012.06.020

Veronneau, M. H., \& Dishion, T. J. (2010). Predicting change in early adolescent problem behavior in the middle school years: A mesosystemic perspective on parenting and peer experiences. Journal of Abnormal Psychology, 38, 1125-1137. http://dx.doi.org/10.1007/s10802-010-9431-0

Warr, M. (1993). Parents, Peers and Delinquency. Social Forces, 72, 247-264. http://dx.doi.org/10.2307/2580168

Warr, M. (2005). Making delinquent friends: Adult supervision and children's affiliations. Criminology, 43, 77-106. http://dx.doi.org/10.1111/j.0011-1348.2005.00003.x

Wikström, P. H., Oberwittler, D., Treiber, K., \& Hardie, B. (2012). Breaking rules: The social and situational dynamics of young people's urban crime. Oxford: Oxford University Press.

Wood, M. D., Read, J. P., Mitchiell, R. E., \& Brand, N. H. (2004). Do parents still matter? Parent and peer influences on alcohol involvement among recent high school graduates. Psychology of Addictive Behaviors, 18, 19-30.

Worthen, M. G. F., (2012). Gender Differences in Delinquency in Early, Middle, and Late Adolescence: An Exploration of Parent and Friend Relationships. Deviant Behavior, 33, 282-307. http://dx.doi.org/10.1080/01639625.2011.573421

\section{Notes}

Note 1 . The sample employed in this study is not fully representative of the city of Malmö, with both adolescents of foreign background and adolescents from the more disadvantaged areas of the city being somewhat underrepresented. When it comes to the variable measuring family composition (living with both parents / single parent family) the information is drawn from the parent interviews in the initial phase of the study. 
Note 2. The frequencies for sniffing and drug use are weighted. Of those who reported that they had tried drugs (T1: $2.6 \%$; T2: $12.1 \%$; T3: $15.3 \%$ ), all had used cannabis. A majority of the adolescents did not engage in much substance use and the scale is skewed.

Note 3. This measure has been defined in many different ways, such as monitoring, supervision and parental knowledge. The definition used in this study has previously been used by Laird and colleagues (2003).

Note 4. The chi-square statistic compares the observed covariance matrix to the matrix expected given the proposed models. A non-significant chi-square value indicates a good fit. The comparative fit index (CFI) ranges from 0-1, with values greater than $.95 / .90$ indicating a good fit. The root mean square error of approximation (RMSEA) is the average amount of error found in the parameter estimates of the models. An RMSEA value below .05 indicates a well-fitting model (Kline, 2005).

Note 5. It should be noted that the influences and correlations associated with the study variables are likely to have reciprocal effects and thus in theory, many of the paths could be reversed. For example, parental knowledge has been suggested both to influence and to be influenced by youth behavior (Laird et al., 2003; Keijsers et al., 2010). The aim of the study has not been to test reciprocal effects, but we have no intention of arguing that these effects do not exist. Also, when testing alternative/reverse path models, the fit between the data and the models was not as good as in the model presented here. Nonetheless, in forthcoming studies it will be possible to conduct a more focused elaboration of reciprocal relationships among the variables as a result of the longitudinal design of the MINDS study.

\section{$(\mathrm{cc}) \mathrm{BY}$}

This work is licensed under a Creative Commons Attribution 3.0 License. 